\title{
Reducing infection risk in implant-based breast-reconstruction surgery: challenges and solutions
}

\section{Adrian SH Ooi ${ }^{1,2}$ \\ David H Song'}

'Section of Plastic and Reconstructive Surgery, University of Chicago Medicine and Biological Sciences, Chicago, IL, USA; ${ }^{2}$ Department of Plastic, Reconstructive, and Aesthetic Surgery, Singapore General Hospital, Singapore
Correspondence: David H Song Section of Plastic and Reconstructive Surgery, University of Chicago Medicine and Biological Sciences, Room J64I, MC 6035, 584I South Maryland Avenue, Chicago, IL 60637, USA

Tel +l 7738340526

Email dsong@surgery.bsd.uchicago.edu
This article was published in the following Dove Press journal:

Breast Cancer - Targets and Therapy

I September 2016

Number of times this article has been viewed

Abstract: Implant-based procedures are the most commonly performed method for postmastectomy breast reconstruction. While donor-site morbidity is low, these procedures are associated with a higher risk of reconstructive loss. Many of these are related to infection of the implant, which can lead to prolonged antibiotic treatment, undesired additional surgical procedures, and unsatisfactory results. This review combines a summary of the recent literature regarding implant-related breast-reconstruction infections and combines this with a practical approach to the patient and surgery aimed at reducing this risk. Prevention of infection begins with appropriate reconstructive choice based on an assessment and optimization of risk factors. These include patient and disease characteristics, such as smoking, obesity, large breast size, and immediate reconstructive procedures, as well as adjuvant therapy, such as radiotherapy and chemotherapy. For implant-based breast reconstruction, preoperative planning and organization is key to reducing infection. A logical and consistent intraoperative and postoperative surgical protocol, including appropriate antibiotic choice, mastectomy-pocket creation, implant handling, and considered acellular dermal matrix use contribute toward the reduction of breast-implant infections.

Keywords: implant infection, risk reduction, acellular dermal matrix

\section{Introduction}

As awareness of options among the population increases, postmastectomy breastreconstruction rates are on the rise. While autologous tissue provides the most natural and lasting outcomes, implant-based breast reconstruction continues to be the more popular option, accounting for close to $80 \%$ of procedures. ${ }^{1,2}$ Reasons for this include no donor-site morbidity, shorter procedures, a younger patient population, a lack of autologous donor tissue, and a rise in bilateral mastectomies. ${ }^{3,4}$

Implant-based breast reconstruction includes one- or two-stage breast-reconstructive procedures where an expander or permanent implant is placed to restore breast contour, with or without the use of reinforcing materials, such as an acellular dermal matrix (ADM). While convenient, implant-based reconstructive procedures do have their disadvantages. Postoperative complications, such as mastectomy-skin necrosis and reconstructive failure, are higher., ${ }^{5,6}$ Patient satisfaction is lower with implant reconstruction compared to autologous tissue, and more patients require secondary revision procedures. ${ }^{7}$

As with any foreign prosthetic material inserted into the body, infection remains the most common and probably the most dreaded risk of implant-based 
breast reconstruction. ${ }^{8}$ Infection of prostheses can lead to complications, ranging from the mild, such as superficial cellulitis, to the severe, including repeated procedures for chronic wounds, implant failure, and life-threatening sepsis. ${ }^{9}$ Specific to breast implants, infection can lead to the development of persistent biofilm and capsular contracture, rib osteomyelitis, and delay in oncologic treatments. ${ }^{2,10}$

For the breast, sequelae and severity of implant infection can generally be divided into infections not requiring surgical intervention and those that require surgical intervention. The former include prolonged hospital stay, increased need for antibiotics, and increased patient distress. The latter include wound debridement, removal of implant, and conversion to autologous reconstruction. The reported overall breastprosthetic infection rates range widely from $1 \%$ to $35 \%{ }^{6,11-13}$ A 2008 article examining the cost of all breast surgery-related surgical site infections (SSIs) in the US estimated this at $\$ 4,091$ per patient, which would probably be higher now with the rise of health care costs and multidrug-resistant organisms. ${ }^{14}$ In terms of time of presentation of infection, $50 \%$ occur more than 30 days after the procedure, making it an issue not just with surgery but with follow-up as well. ${ }^{11}$

Adding to the milieu has been the introduction of ADM. While helping to improve implant-based reconstruction esthetic outcomes and increasing possible intraoperative size and fill, the use of ADM has been shown to be associated with higher rates of overall complications, seroma, infection, and reconstructive failure. ${ }^{8}$

Breast implant-related infection continues to be a prevalent and important problem, leading to a strain on health care systems and patients. However, it is not unavoidable, as shown by the wide variation in reported infection rates, nor is it isolated, with studies showing no difference in SSIs between autologous, prosthetic, and hybrid immediate breastreconstructive procedures. ${ }^{15}$

The aim of this review is to summarize the literature and identify the factors leading to increased risk of implant-based breast reconstruction-related infection, with a particular emphasis on the accumulated knowledge since the turn of the century. We combine this with our personal experience and present solutions to each of the challenges raised. We seek to provide practical guidelines to reduce breast implantinfection risk through the preoperative, intraoperative, and postoperative processes related to this.

\section{Bacteriology of implant infection}

Understanding the bacteriology of breast prosthesis-related infections will help in determining the source. Most organisms isolated from breast implant-infection cases are Staphylococcus spp., with the most common being $S$. aureus and coagulase-negative staphylococci. ${ }^{11,16-18}$ While the former is a colonizer of skin and requires eradication, the latter is a common skin commensal. In particular, the rate of methicillin-resistant $S$. aureus (MRSA) infections is rising and is associated with a lower rate of implant salvage. ${ }^{19,20}$ Other common Gram-positive bacteria include the Streptococcus spp., although recent reports show a rising incidence of Gram-negative bacterial infections, such as the Pseudomonas spp. ${ }^{21}$

Rare organisms that have caused implant-based breastreconstruction infections include exposure-related Brucella, soil-related Streptomyces, and Pasteurella multocida in a cat owner. ${ }^{22-24}$ Occasionally, nontuberculous mycobacteria and other nonbacterial organisms, such as yeast, have been responsible and thought to be found in the environment of either the patient or surgical team. ${ }^{25-28}$ The presenting clinical features in these infections tend to be indolent, and systemic symptoms are usually absent. A high index of suspicion should be maintained in patients whose apparently delayed onset of symptoms does not respond to first-line antibiotics or who have negative preliminary cultures, and the relevant special investigations such as acid-fast stains and mycobacterial culture ordered. ${ }^{25,29}$ It has been found that atypical organisms, such as Gram-negative bacteria and fungal infections, are associated with lower rates of device salvage. ${ }^{30}$

\section{Biofilm and capsular contracture}

Biofilms occur when cell-cell communication between bacteria leads to the development of an adhesive extracellular polymeric matrix, which acts as a protective barrier against debridement, antibiotics, and antiseptics. ${ }^{31}$ Though considered a subclinical infection, it is a particularly difficult problem with any form of prosthesis, and in the augmentation-mammaplasty literature has been shown to be associated with an increased risk of capsular contracture, which can cause significant esthetic distortion, pain, and distress to the patient. ${ }^{32}$ Furthermore, there may be some association between biofilm and anaplastic large-cell lymphoma development. ${ }^{33}$ The main microbiological causative agent identified in biofilm formation has been coagulase-negative staphylococci, in particular Staphylococcus epidermidis. ${ }^{17}$ Treatment of biofilm-related breast-implant complications is difficult and involves further surgery, prolonged antibiotics, and implant exchange, and thus prevention would be ideal in these situations. 


\section{Risk factors for implant infection}

The first step in preventing breast-implant infection is proper patient selection. This includes a thorough history and physical and correction of any preexisting risk factors. Numerous publications have shown that patient and preoperative factors have a stronger correlation with necrosis and infection than surgical factors. ${ }^{34}$ Table 1 summarizes the significant risk factors from the literature for breast-implant infection and outlines our solutions to each. While the level of evidence for each risk factor is variable, the ability to control for all will lead to optimal patient preparation for surgery.

\section{Patient and disease characteristics}

Many studies have sought to determine patient demographics and comorbidities affecting implant-infection risk. In a single-institute analysis of 57 of 1,170 expander/implant reconstructions who developed postoperative infection, McCarthy et al found that the odds of developing any postoperative complication were significantly increased in smokers, women aged over 65 years, obese patients, and those with hypertension..$^{35}$ In 47 of 981 patients who had an infection before exchange for a permanent implant, Kato et al found that significant risk factors included age $\geq 50$ years, body mass index (BMI) $\geq 25 \mathrm{~kg} / \mathrm{m}^{2}$, and diabetes mellitus, and recommended closer follow-up for the high-risk groups. ${ }^{36}$ Wang et al analyzed the American College of Surgeons' National Surgical Quality Improvement Program (NSQIP) database for 15,978 immediate breast-reconstruction patients and found diabetes mellitus and obesity to be significantly associated with postoperative infection. ${ }^{37}$ In their analysis of 1,211 patients undergoing immediate tissue-expander breast reconstruction, Weichman et al found patient comorbidities of age greater than 50 years, diabetes mellitus, hypertension, hypercholesterolemia, and obesity to be associated with an increased risk of infection. ${ }^{38}$ Conversely, another review of the NSQIP database showed that age has not been found to be a risk factor for implant-based breast-reconstruction infection, though this study used 65 years as the age cutoff. ${ }^{39}$ The risk of high BMI was further evaluated by Chun et al in 415 immediate breast reconstructions. They found that for each $1 \mathrm{~kg} / \mathrm{m}^{2}$ increase in BMI, the odds of developing infection increased by $11 \%{ }^{40}$

In terms of breast size, a single-institution review of 413 tissue expanders placed in 300 women for postmastectomy

Table I Significant risk factors from the literature for the development of implant-based breast-reconstruction infection and proposed interventions

\begin{tabular}{|c|c|}
\hline Risk factor & Intervention \\
\hline \multicolumn{2}{|l|}{ Patient characteristics } \\
\hline \multirow[t]{2}{*}{ - Smoking } & - No smoking for at least 2 weeks prior to surgery \\
\hline & - If patient is still smoking and surgery is nonurgent, delay surgery until compliant \\
\hline - Patient age $>50$ years & - Consider autologous reconstruction \\
\hline \multirow[t]{2}{*}{ - Obesity } & - Consider autologous reconstruction \\
\hline & - If surgery is nonurgent, encourage weight loss and delay reconstruction until patient $\mathrm{BMI}<30 \mathrm{~kg} / \mathrm{m}^{2}$ \\
\hline - Hypertension & - Adequate anti-hypertensive medication \\
\hline - Diabetes mellitus & - Blood-sugar control 70-150 mg/dL \\
\hline - Hypercholesterolemia & - Adequate diet or medication control of cholesterol levels \\
\hline \multirow[t]{2}{*}{ - Larger breast size } & - Advise patient to downsize \\
\hline & - Consider autologous reconstruction \\
\hline \multirow[t]{3}{*}{ - Local or systemic immunocompromised states } & - Normal white-cell count \\
\hline & - Avoid systemic steroid use \\
\hline & - Consider autologous reconstruction \\
\hline \multicolumn{2}{|l|}{ Disease characteristics } \\
\hline - Immediate reconstruction & - Consider delayed and/or autologous reconstruction in higher-risk patients \\
\hline - Bilateral procedures & - Consider delayed and/or autologous reconstruction in higher-risk patients \\
\hline \multirow[t]{3}{*}{ - Mastectomy skin necrosis } & - Close communication with resecting surgeon \\
\hline & - Submuscular placement of implant \\
\hline & - Consider adjuncts, such as incisional negative-pressure wound therapy \\
\hline - Axillary lymph-node procedures & - Perform axillary lymph-node procedures in a separate session premastectomy \\
\hline \multicolumn{2}{|l|}{ Adjuvant therapy } \\
\hline \multirow[t]{2}{*}{ - Radiotherapy } & - Avoid implant reconstruction \\
\hline & - Consider autologous tissue reconstruction \\
\hline - Chemotherapy & - Closer follow-up and early detection of infection \\
\hline
\end{tabular}

Abbreviation: BMI, body mass index. 
breast reconstruction showed significant association of infection with breast size larger than a C cup. ${ }^{41}$ Selber et al also found that the odds of infection increased by $27 \%$ for every $100 \mathrm{~mL}$ increase in preoperative breast volume. ${ }^{42}$

Active smoking has been shown to be associated with increased risk of mastectomy-flap necrosis and reconstructive failure. In a single-center study of 1,952 implant-based breast-reconstructive procedures, Reish et al identified smoking as a significant risk factor for implant infection. ${ }^{19}$ Immunosuppressed states and such associations as steroid use lower the local and systemic immune system and should be avoided. ${ }^{43}$

When looking at the timing of reconstruction, Alderman et al found that immediate breast-reconstructive procedures were associated with higher complication rates, regardless of the type of reconstruction, with a trend toward higher infection in implant-based reconstruction versus free transverse abdominis myocutaneous flap procedures $(35.4 \%$ versus $17.9 \%){ }^{6}$ An NSQIP review of 2,285 consecutive implant-based breast procedures by Cohen et al found the infection rate was highest in mastectomy and immediate tissue-expander reconstructive procedures. ${ }^{11}$

Nahabedian et al were among the earliest to suggest an association between lymph-node dissection and implant infection. ${ }^{44}$ In their series of 168 procedures, there was a suggestion that simultaneous lymph-node dissection was associated with a 6.29-fold higher chance of implant infection. Further to this, Selber et al analyzed risk factors for complications in 564 cases of implant-based breast reconstructions with the use of ADM. Sentinel lymph-node biopsy was found to increase the risk of a postoperative infection by 2.45 times. ${ }^{42}$ At our institute, sentinel lymph-node biopsy is done as a separate procedure from the resection, minimizing axillary procedures during the mastectomy.

Finally, it follows that mastectomy skin-flap necrosis will lead to a higher risk of infection, and this has been corroborated by numerous authors. ${ }^{11,19}$ While postmastectomy skin-flap viability is commonly the responsibility of the oncologic resecting surgeon, the plastic surgeon can play a role in maximizing this by close communication, placing the healthy pectoralis muscle beneath the skin flap, and by reducing mastectomy skin tension postclosure through adjuncts, such as incisional negative-pressure wound therapy. ${ }^{45}$

\section{Adjuvant therapies}

\section{Radiotherapy}

Multiple studies have shown radiation to place implantbased breast-reconstruction procedures at higher risk of infection. ${ }^{19,32,34,38,42,44,46}$ With an overall $6 \%$ infection rate in 168 implant-based breast-reconstructive procedures, Nahabedian et al found a 4.88-fold greater chance of implant infection in patients with prior radiation therapy. ${ }^{44}$ Weichman et al analyzed 1,211 patients undergoing immediate tissueexpander breast reconstruction and found prior breast radiation to be significantly associated with a higher risk of infectious complications. ${ }^{38}$ This was corroborated by Kearney et al in 210 patients, who found that patients receiving postoperative radiotherapy compared with no radiotherapy were at a higher risk of experiencing expander infection. ${ }^{46}$ Selber et al analyzed risk factors for complications in 564 cases of implant-based breast reconstructions with the use of ADM. Patients who underwent postoperative radiation therapy were more than twice as likely to develop a postoperative infection. ${ }^{42}$ Sbitany et al analyzed 580 patients who had undergone 903 reconstructions, specifically looking at the effect of radiation and total skin-sparing mastectomy on outcomes. ${ }^{47}$ They found that any radiation delivery caused an increased rate of infection requiring antibiotics $(21.6 \%)$.

\section{Chemo- and hormonal therapy}

A few studies have attempted to determine the effect of chemotherapy on postoperative breast-implant infection. ${ }^{19,44,48,49}$ Peled et al analyzed 163 patients who underwent mastectomy and immediate reconstruction, including $66 \%$ implant-based and $33 \%$ autologous tissue-based reconstructions. ${ }^{48}$ The adjuvant-chemotherapy group had a significantly higher number of infections (44\%) versus the neoadjuvant- and no-chemotherapy groups ( $23 \%$ and $25 \%$, respectively). This finding was corroborated by Reish et al in an analysis of 1,952 immediate implant-based reconstructions, though it was not clearly stated whether the chemotherapy was adjuvant or neoadjuvant. ${ }^{19}$ However, it is interesting to note that the American Society of Plastic Surgeons clinical practice guideline committee determined that this risk was nonsignificant. ${ }^{49}$

\section{Risk reduction in surgery Preoperative factors}

\section{Surgical team and operating environment}

To deliver the best-possible outcomes for the patient, surgical teams and protocols should be well established (Table 3), with each individual on the team taking personal responsibility for his or her duty of care. ${ }^{50}$ Every member of the surgical team should be adequately gowned and prepared to minimize contamination to the surgical field. This includes the concealment of as much facial hair as possible, including face shields to prevent eyebrow dandruff from falling onto 
the patient. If possible, staff should be screened regularly for potential pathologic bacteria. ${ }^{28,51} \mathrm{~A}$ prospective randomized controlled trial of disposable versus reusable gowns and drapes in implant-based breast reconstruction points to reduced infection with the use of disposable gowns. ${ }^{52}$

In an interesting article examining the impact of oncologic and plastic surgical teams on immediate implant-based breast-reconstruction outcomes, Gfrerer et al found that surgical teams that worked together on fewer than 150 procedures had a 2.48-fold higher infection rate than teams with more than 301 procedures, with a trend toward lower rates of both skin necrosis and infection in teams with a greater number of procedures performed. ${ }^{34}$ Francis et al found a significant covariate for increased breast-expander infection risk to be more than one surgical oncologist. ${ }^{41}$

The operating room (OR) environment should be optimized to preserve sterility. Systems touted to lower SSIs include rooms with laminar airflow, filtered air exchange, and positive pressure. ${ }^{51}$ Some investigators advocate the placement of high-particulate air filters outside the OR to direct the contaminants toward the door. ${ }^{53}$ High flow of human traffic in and out of the OR has been shown to increase the number of bacterial colony-forming units in the room significantly, and thus should be limited. ${ }^{54}$

\section{Perioperative antibiotics}

Perioperative antibiotics have been a point of contention for clean surgical procedures, under which most breastreconstructive procedures are classified. This controversy was intensified by the publication of guidelines for the prevention of SSIs, which recommended a single dose of preoperative antibiotics. ${ }^{55}$ Subsequently, plastic surgeons sought to determine the effectiveness of these guidelines in preventing infection for implant-based breast procedures.

A systematic review of antibiotic use in immediate breast reconstruction showed a $14.4 \%$ rate of infection in procedures without perioperative antibiotic prophylaxis versus $5.8 \%$ in procedures with 24 hours of perioperative antibiotic prophylaxis. ${ }^{12}$ In all, $65 \%$ of their procedures involved a breast expander or implant.

Clayton et al conducted a retrospective study comparing patients undergoing implant-based breast reconstruction who received preoperative and postoperative prophylactic antibiotics until drains were removed with a group who received only a single dose of preoperative antibiotic. ${ }^{56}$ The overall rate of SSIs increased from $18.1 \%$ in 116 patients who received pre- and postoperative antibiotics to $34.3 \%$ in the 134 patients receiving a single dose. Similarly, infections requiring reoperation increased from $4.3 \%$ to $16.4 \%$. Patients in the single-dose group were 4.74-fold more likely to develop an SSI requiring reoperation.

Avashia et al sought to determine if prolonging the use of antibiotics beyond the Centers for Disease Control and Prevention-recommended 24-hour period was necessary for patients undergoing implant-based breast reconstruction with ADM. ${ }^{57}$ In 138 procedures, they found that prolonging oral antibiotic use for 48 hours or more beyond the perioperative 24-hour intravenous antibiotics use reduced the infection rate from $31.6 \%$ to $6.7 \%$.

In terms of type of antibiotic, commonly recommended antibiotics include an intravenous first- or second-generation cephalosporin. This should be administered 30-60 minutes before the surgical skin incision and redosed as per hospital protocol. In patients with allergies to $\beta$-lactam antibiotics, a non- $\beta$-lactam antibiotic with adequate spectrum, such as clindamycin, is recommended. ${ }^{58} \mathrm{~A}$ review of the NSQIP database for breast implant-associated infections in 2,285 procedures showed that all Gram-positive organisms were sensitive to vancomycin, linezolid, tetracycline, and doxycycline, while all Gram-negative organisms were sensitive to gentamicin and cefepime. ${ }^{11}$ Another step further would be the use of oral antibiotics for the days preceding the implant procedure to eradicate endogenous $S$. aureus, as has been suggested by Silvestri et al. ${ }^{59}$

Mirzabeigi et al examined the role of different perioperative antibiotic regimens in 51 high-risk patients with previously radiated chest walls. ${ }^{60}$ The control group received 5-7 days of a cephalosporin postoperatively, while the study group received a 30-day course of double-strength trimethoprim-sulfamethoxazole administered twice daily, chosen because of its broad antimicrobial coverage costeffectiveness, ease of administration, and relative safety. The infection rate for the control group was 35\%, significantly higher when compared to $8 \%$ in the study group.

\section{Preoperative planning and implant selection}

Adequate preoperative analysis and planning based on patient breast measurements, skin and soft-tissue assessment, and patient preferences will allow proper implant selection and avoid the need for multiple sizer insertions intraoperatively. ${ }^{61}$

When comparing direct-to-implant (DTI) versus twostage tissue expander followed by implant-exchange procedures, a 2015 meta-analysis showed that while the risk of skin-flap necrosis was higher for DTI cases, there was no significant difference in terms of infection rates. ${ }^{62}$ This was 
corroborated by a review of the NSQIP database of 2,285 consecutive implant-based breast procedures that same year, which showed an infection rate of $6.1 \%$ for tissueexpander reconstruction and no significant difference with DTI procedures. ${ }^{11}$

In terms of implant size and expander fill, Selber et al found that in 564 cases of DTI with the use of ADM, odds of infection were fourfold higher with an intraoperative expander-filling volume greater than $50 \%$ of the total volume, with an absolute intraoperative fill volume greater than 300 $\mathrm{mL}$ associated with double the explantation risk. ${ }^{42}$

When comparing the rate of infection with regard to implant texture and filling, there are no significant differences in terms of infection. ${ }^{63}$ However, an in vitro study showed that textured implants develop a significantly higher load of biofilm, although this was not translatable to increased capsular contracture, as this occurred when a threshold of biofilm on either surface was reached. ${ }^{64}$

In cases where there is insufficient or doubtful local tissue for coverage of the breast implant, it may be prudent to plan for additional autologous, well-vascularized tissue to reinforce the construct. This is even more pertinent in previously radiated breasts. In 1,000 consecutive cases of implant-based breast reconstructions, Chang et al found that in previously radiated breasts, free transversus abdominis myocutaneous (TRAM) flap/implant reconstructions had a significantly lower implantloss rate than patients with expander/implant-only reconstructions $(5 \%$ versus $30.3 \%) .{ }^{65}$ When comparing pedicled latissimus dorsi/implant and free TRAM flap/implant reconstructions with expander/implant-only reconstructions, there was a significantly lower implant-failure rate. When looking specifically at infection, there was a $12.1 \%$ infection rate in the expander/ implant-only group, compared to $6.1 \%$ in the latissimus dorsi/ implant and 0 in the TRAM flap/implant groups, though the analysis did not reach statistical significance.

\section{Intraoperative factors}

An efficient, considered approach at every point of the procedure will help minimize infection risk (Table 4). Khansa et al showed that implementation of a standardized best-practice protocol led to a significant decrease in breast implant-infection rates. ${ }^{50}$ This standardization has the added advantage of reducing operating times, which has been shown to be associated with decreased SSIs. ${ }^{37}$

\section{Skin preparation and draping}

An aseptic surgical technique begins with adequate skin cleansing. Contrary to popular belief, preoperative showering with chlorhexidine versus no showering has shown no differences in rates of SSIs. ${ }^{66}$ The exception is patients who are known carriers of MRSA, where decontamination with a 5-day course of topical mupirocin and daily chlorhexidine body scrub is recommended. ${ }^{67}$

Preincisional painting of the skin with solutions containing high levels of alcohol ( $95 \%-100 \%)$, chlorhexidine, or iodine has been proven to kill skin commensals, in particular MRSA. ${ }^{68}$ In particular, the combination of alcohol and chlorhexidine has been proven to be superior to povidone-iodine, with a $9.5 \%$ SSI rate for the former versus $16.1 \%$ for the latter. ${ }^{69}$

The milk ducts of the breast have been identified as a significant source of $S$. epidermidis. ${ }^{70}$ This area should be avoided if possible and recleaned as necessary intraoperativel. ${ }^{50}$ Nipple shields have been advocated as a way to reduce bacterial contamination. In 43 patients undergoing breast implant-based procedures, Collis et al took swabs from the nipple area immediately after skin preparation with povidone-iodine, applied an adhesive dressing to the nipple, and took further bacterial swabs from above and below the shield at the conclusion of each procedure. ${ }^{71}$ None of the swabs from above the nipple shield were positive, but $33 \%$ of the swabs from under the shields were positive. In a control group without nipple shields, the positive swabs from the nipple at procedure conclusion comprised $71 \%$.

After skin cleansing, proper draping will help to isolate the surgical field. The ideal drape should act as a barrier to fluid and tissue, have an infection benefit, and maintain functionality and cost-effectiveness. A prospective randomized trial of 102 patients comparing disposable materials to reusable laundered drapes showed a zero infection rate in the former compared with a $12 \%$ infection rate at 30 days postoperatively in the latter. ${ }^{52}$ Cost was shown to be similar for both groups.

\section{Mastectomy and pocket preparation}

In an immediate implant-based reconstruction, communication between the resecting and reconstructive surgeons is important. Incisions and the ability to spare skin should be discussed, and the optimal approach agreed upon. The mastectomies should be done with minimal trauma to the skin and surrounding tissue, removing all breast tissue but maintaining the skin, its subcutaneous tissue, and vascular plexuses. Excessive stretching or cautery to the skin should be avoided. Hemostasis should be secured at the end of the mastectomy, and the mastectomy pocket washed with the resecting surgeon's irrigation solution of choice. The reconstructive surgeon then enters the field, and ideally the 
field should be reprepared and a fresh set of instruments used. Talc-free gloves are recommended. Sub-pectoralis major pocket dissection should be done under direct vision to fit the implant precisely. Blunt dissection should be avoided, and particular attention should be paid to hemostasis.

In an exchange of an expander for an implant, the reconstructive surgeon has control over the access. Original incision points should be used, and if possible a differential shelving incision can be made to the skin and the muscle/ADM to avoid the incisions lying on top of each other. Care must be taken to avoid damage to the expander en route to the pocket.

Once prepared, the pockets are irrigated with normal saline followed by a mixed antibiotic or povidone-iodine solution. This, along with soaking of the implant, has been shown to reduce the risk of infection as well as capsular contracture, which has been theorized to be related to persistent low-grade infection. ${ }^{17,72-74}$ Adams et al analyzed 63 implant-based breast-reconstructive procedures and the efficacy of triple-antibiotic solution $(50,000 \mathrm{U}$ bacitracin, $80 \mathrm{mg}$ gentamicin, $1 \mathrm{~g}$ cefazolin in $500 \mathrm{~mL}$ normal saline) in reducing capsular contracture. ${ }^{73}$ There was a $9.5 \%$ rate of capsular contracture, which was lower than historical rates. They also reported on the cost-effectiveness of the solution compared with reoperation for capsular contracture and recommended alternatives in cases of antibiotic allergies (Table 2). In a meta-analysis of 1,786 patients receiving breast augmentation with saline or silicone implants, Yalanis at al found that compared with saline irrigation, povidone-iodine irrigation of the implant reduced the development of Baker III/IV capsular contracture. ${ }^{75}$ Previous fears of implant weakening or rupture due to povidone-iodine irrigation have been refuted with an implant-deflation rate of much less than $1 \%{ }^{76}$

\section{Lower-pole reinforcement and the use of ADM}

The benefits of ADM in implant-based breast reconstruction are extra support, decreased pain, improved esthetics,

Table 2 Recommended antibiotic irrigation solutions ${ }^{73}$

\begin{tabular}{|c|c|}
\hline Allergen & Recommended irrigation solution \\
\hline First line/iodine allergy & $\begin{array}{l}50,000 \mathrm{U} \text { bacitracin, } 80 \mathrm{mg} \text { gentamicin, I g } \\
\text { cefazolin, } 500 \mathrm{cc} \text { normal saline }\end{array}$ \\
\hline$\beta$-Lactam antibiotics & $\begin{array}{l}250 \mathrm{cc} \text { povidone iodine solution, } 80 \mathrm{mg} \\
\text { gentamicin, } 250 \mathrm{cc} \text { normal saline }\end{array}$ \\
\hline Bacitracin & $\begin{array}{l}50 \mathrm{cc} \text { povidone-iodine solution, I g cefazolin, } \\
80 \mathrm{mg} \text { gentamicin, } 500 \mathrm{cc} \text { normal saline }\end{array}$ \\
\hline Aminoglycosides & 250 cc povidone-iodine, 250 cc normal saline \\
\hline \multicolumn{2}{|c|}{$\begin{array}{l}\text { Note: Reprinted from Adams WP Jr, Rios JL, Smith SJ, Enhancing patient outcomes } \\
\text { in aesthetic and reconstructive breast surgery using triple antibiotic breast irrigation: } \\
\text { six-year prospective clinical study. Plast Reconstr Surg. 2006; I I8(7 Suppl):46S-52S. } \\
\text { Promotional and commercial use of the material in print, digital or mobile device } \\
\text { format is prohibited without the permission from the publisher Wolters Kluwer. } \\
\text { Please contact healthpermissions@wolterskluwer.com for further information. }\end{array}$} \\
\hline
\end{tabular}

and effective lower-pole expansion., ${ }^{57-79}$ However, its use is still controversial, due to some reports indicating increased risks of infection, seroma, and flap necrosis. ${ }^{8,42}$ Logically speaking, the presence of more foreign material over a larger surface area would equate to a higher risk of infection.

Chun et al conducted a retrospective review of 283 patients where 269 reconstructions were performed using tissue expanders or implants with ADM, and 146 reconstructions were performed without ADM. ${ }^{40}$ The infection $(8.9 \%$ versus $2.1 \%$ ) rates were significantly higher in the ADM group. A meta-analysis of ADM use in submuscular breastimplant reconstruction showed a significantly higher risk of infection with ADM, leading to an increased relative risk of infection of 2.47-fold. ${ }^{8}$

Conversely, Vardanian et al reported their experience with 337 immediate expander-based breast reconstructions, with and without ADM (61.7\% versus $38.3 \%)$, and found no difference in the incidence of postoperative infection, with better esthetic results related to the use of ADM. ${ }^{79}$ This was corroborated by Sbitany and Serletti in a systematic review of ADM and prosthetic-based breast reconstruction. ${ }^{80}$ In an analysis of 331 patients, Colwell et al found no significant difference in the rate of complications, and concluded that the use of ADM was cost-effective. ${ }^{5}$ They did, however, note the presence of a learning curve with more complications in the first year of using ADM.

In a direct comparison of different types of ADM in immediate implant-based breast reconstruction, Ranganathan et al compared 123 cases where AlloDerm (LifeCell Corporation, Bridgewater, NJ, USA) was used to 186 where FlexHD (Ethicon Inc, Somerville, NJ, USA) was used. ${ }^{81}$ They found a significantly higher rate of major $(17.7 \%$ versus $8.1 \%)$ and minor ( $4.8 \%$ versus $3.8 \%$ ) infections in the patients who received FlexHD compared with those who received AlloDerm. The postulated reasons were differences in processing and higher inflammation with FlexHD. Separately, an analysis of risk factors for complications in 564 two-stage implant-based breast reconstructions found no significant differences in infectious or other complications when using human ADM and bovine ADM. ${ }^{42}$

Some surgeons have sought to overcome the need for ADM by the use of the patient's native tissue to reinforce the lower pole of the pectoralis major muscle. The use of serratus fascia is common, though often thin and limited. Gentileschi et al described the novel use of a dermal-adipose flap in 23 immediate breast reconstructions via a Wise-pattern approach. ${ }^{82}$ They reported no infections in their small patient population. However, the use of native tissue may not always 
be feasible or available, especially in cases where larger implants are inserted.

It should be noted that the use of ADM has been associated with the phenomenon of "red-breast syndrome". ${ }^{83}$ This presents as painless blanching erythema of the inferior breast overlying the ADM site. It is not thought to be an infection and could be due to a variety of factors, including dependent erythema, interruption of lymphatic flow, histamine release, or vascular ingrowth. It often resolves spontaneously in a matter of weeks, although if there is any suspicion of infection at all, treatment protocols should still be implemented. ${ }^{84}$

Pocket preparation involves creating the ideal environment for implant opening and insertion, to minimize any contamination and time of exposure of the implant. While there is conflicting evidence of ADM increasing the risk of infection, if planned for, this should be stitched in first, allowing for an adequately sized single point of entry into the pocket (Figure 1).

\section{Implant handling and insertion}

As much as possible, breast implants or expanders should receive minimal handling and exposure to the environment between the time of package opening and closure of incisions. To this end, the implant should only be opened once the surgeon is sure of the implant required and immediately prior to insertion into the breast pocket. Once opened, the implant should be handled only by a single surgeon. Implant irrigation has been shown to reduce implant infection, and should be poured into the opened packaging (Table 2 for recommended solution). ${ }^{73}$
Once the implant and pocket have been irrigated, the skin surrounding the incision should be cleaned once again with povidone-iodine and left to dry. Use of a transparent waterproof adhesive film reinforcement as a barrier around the incision has been described, but is not absolutely necessary with proper cleansing. ${ }^{85}$ Anyone handling the implant directly should change their sterile gloves aseptically for a fresh, talc-free pair immediately prior to inserting the implant. The implant should be inserted with minimal skin contact, using retractors, or an introduction sleeve. ${ }^{17,86}$

\section{Closure and drains}

Closure of the pectoralis major/ADM and skin should be performed in layers. To reduce the risk of infection further, absorbable monofilament sutures are recommended over polyfilament, which can harbor bacteria. ${ }^{77}$

The placement of postoperative drains is important in reducing dead space and removing excess fluid and blood, which can become a nidus for infection. However, there is the fear that a drain catheter can become a point of entry for bacteria into the wound. In a direct comparison of 1,495 reconstructions where drains were placed versus 951 where no drains were used, McCarthy et al found no difference in the overall rate of complications or incidence of infection necessitating implant removal. ${ }^{87}$ However, in an analysis of 323 immediate expander-with-ADM breast reconstructions, Hanna et al found that prolonged drain use of more than 21 days was a significant risk factor for infection, with an odds ratio of $3.3 .^{2}$

In terms of methods to reduce infection in patients with drains after implant insertion, Murray et al reviewed 200

A

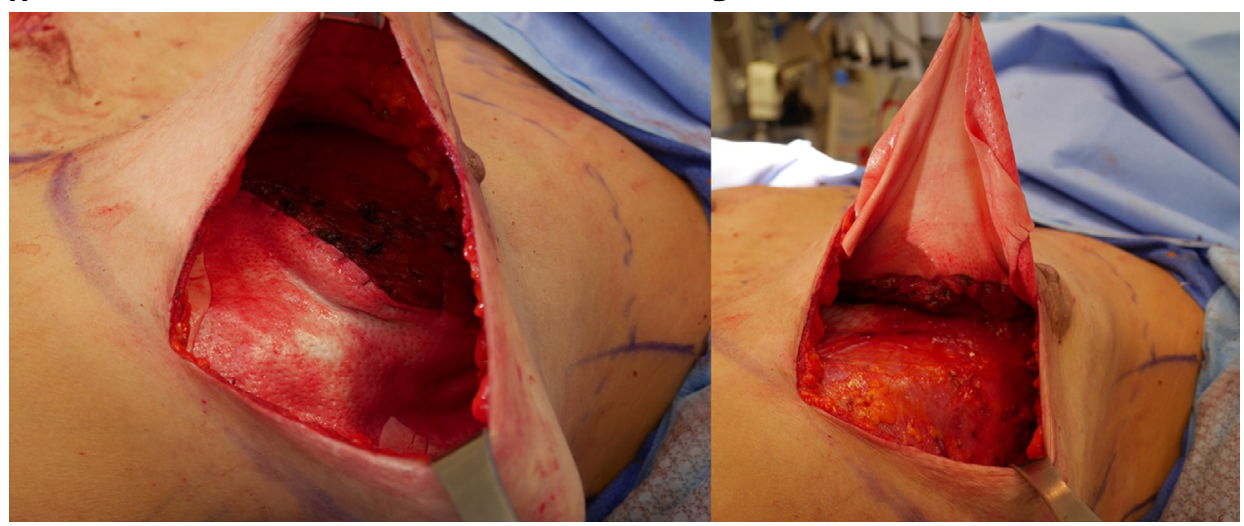

Figure I Inframammary skin-sparing mastectomy approach demonstrating suture of ADM to PM muscle prior to insertion of implant.

Notes: (A) ADM sutured with absorbable monofilament to lower lateral edge of PM muscle and (B) ADM reflected upward, showing pocket for insertion of implant. Abbreviations: ADM, acellular dermal matrix; PM, pectoralis major. 
cases of tissue-expander use before and after the implementation of a drain protocol, which included the use of topical mupirocin around the drain site, reinforcement with either AlloDerm or subcutaneous tunneling, and removal before the end of the first postoperative week. ${ }^{88}$ The infection rate was zero in the protocol group and 5.65\% in the preprotocol group.

\section{Postoperative factors}

Most implant-based breast-reconstructive operations can be done as ambulatory procedures. In a review of 195 patients, Leyngold et al found that inpatient stay (16-fold) is a significant risk factor for development of periprosthetic infection. ${ }^{89}$

While the incisions are healing and the drains are in situ, usually a minimum of 2 weeks, patients should avoid contact with potential contaminants, such as soil and even cats, as organisms have a predilection for adhesion to implants. ${ }^{22}$ Procedures that place the implant at risk of infection, such as nipple piercing, should be avoided if possible, even after the surgical wounds have closed.$^{90}$ In the longer term, prophylactic antibiotics for bacteremic procedures has been recommended for patients with breast implants. ${ }^{17,91}$

It is important to follow-up patients beyond the first month. In a review of the NSQIP database of 2,285 consecutive breast implant-related procedures, it was found that only
$50 \%$ of infections presented within the first 30 days postoperatively, with a mean time to explantation of 41 days. ${ }^{11}$

\section{Conclusion}

While it is difficult to avoid surgical infections completely, the risk of infection in implant-based reconstruction can be minimized. This is extremely important to minimize patient distress and further costs. Infection prevention begins with an understanding of the bacteriology and reduction of patient risk factors (Table 1). Our steps to reduce infection, made up of a mix of an experiential learning curve and of following the evidence, takes into consideration the factors contributing to infection, and are summarized in Tables 3 and 4. Postoperative follow-up beyond 1 month is necessary to assess for complications and outcomes, and for early detection and treatment of infection if it does occur. With a vast literature surrounding this topic, there are varying levels of evidence for each factor. While by no means exhaustive, this article has provided a general summary of the significant challenges, with practical solutions. Further prospective studies, systematic reviews, and meta-analyses would help to shed more light on specific challenges and solutions.

\section{Disclosure}

The authors report no conflicts of interest in this work.

Table 3 Perioperative guidelines for reducing infection in implant-based breast reconstruction

\begin{tabular}{|c|c|}
\hline Challenge & Solution \\
\hline \multicolumn{2}{|l|}{ Surgical team and environment } \\
\hline \multirow[t]{2}{*}{ - Colonization of patient } & - Screening for MRSA and eradication as indicated \\
\hline & - Avoidance of activities placing patient at risk of colonization \\
\hline \multirow[t]{2}{*}{ - Colonization of medical staff } & - Regular screening \\
\hline & - Strict barrier controls \\
\hline - Colonization of operating room & - Hygienic operating room environment with laminar airflow systems \\
\hline \multirow[t]{2}{*}{ - Multiple surgical teams } & - Familiar high-volume surgical teams \\
\hline & - Low operating room traffic \\
\hline \multicolumn{2}{|l|}{ Perioperative antibiotics } \\
\hline - Timing & - 30-60 minutes before surgical skin incision \\
\hline \multirow[t]{3}{*}{ - Duration } & - Intravenous for at least 24 hours \\
\hline & - Total of I week antibiotic use \\
\hline & - Consider prolonging antibiotic use in high-risk or previously irradiated patients \\
\hline - Antibiotic choice & $\begin{array}{l}\text { - First-line antibiotic of choice is first-generation cephalosporin, with clindamycin } \\
\text { in } \beta \text {-lactam antibiotic-sensitive patients }\end{array}$ \\
\hline - Known carriers of MRSA or areas where MRSA is prevalent & - Intravenous vancomycin perioperatively \\
\hline \multicolumn{2}{|l|}{ Preoperative planning } \\
\hline \multirow[t]{2}{*}{ - Operative time } & - Preoperative dimensional planning \\
\hline & - Minimize operative time through standardized protocols \\
\hline - Implant choice & $\begin{array}{l}\text { - Smooth, round silicone implants are adequate for the majority of implant-based } \\
\text { reconstructive cases }\end{array}$ \\
\hline - Expander fill & - Keep intraoperative expansion to $<50 \%$ or $<300 \mathrm{~mL}$ \\
\hline - Insufficient/doubtful mastectomy skin flaps & - Consider autologous flap reinforcement \\
\hline
\end{tabular}

Abbreviation: MRSA, methicillin-resistant Staphylococcus aureus. 
Table 4 Operative sequence and steps to reduce infection in implant-based breast reconstruction

\begin{tabular}{|c|c|}
\hline Challenge & Solution \\
\hline \multicolumn{2}{|l|}{ Skin preparation and draping } \\
\hline \multirow[t]{2}{*}{ - Operative skin preparation } & - Chlorhexidine with $95 \%$ alcohol skin preparation \\
\hline & - Disposable drapes \\
\hline - Breast milk-duct colonization & - Shield implant from contamination by nipple-duct flora \\
\hline - MRSA carriers & -5-day course of topical mupirocin and daily chlorhexidine body scrub \\
\hline \multicolumn{2}{|l|}{ Mastectomy and pocket preparation } \\
\hline \multirow[t]{3}{*}{ - Adequate recipient-site preparation } & - Communication with resecting surgeons \\
\hline & - Minimize trauma to mastectomy skin flaps \\
\hline & - Meticulous hemostasis \\
\hline \multirow[t]{2}{*}{ - Implant-pocket preparation } & - Precise pocket dissection \\
\hline & - Triple-antibiotic or povidone-iodine irrigation \\
\hline \multicolumn{2}{|l|}{ Lower-pole reinforcement } \\
\hline \multirow[t]{3}{*}{ - Use of acellular dermal matrix (ADM) } & - Aseptic technique even more important \\
\hline & - Consider native tissue reinforcement if available \\
\hline & - Suture in place before implant placement \\
\hline \multirow[t]{2}{*}{ - Red-breast syndrome } & - Can occur with ADM use \\
\hline & - Early treatment if any suspicion of infection \\
\hline \multicolumn{2}{|l|}{ Implant handling and insertion } \\
\hline \multirow[t]{6}{*}{ - Minimize contamination of implant } & - Single surgeon handling implant \\
\hline & - Fresh pair of talc-free gloves \\
\hline & - Reclean implant-entry site with povidone-iodine \\
\hline & - Minimize implant-exposure time \\
\hline & - Triple-antibiotic irrigation of implant in packaging \\
\hline & • "No-touch" insertion technique \\
\hline \multicolumn{2}{|l|}{ Closure and drains } \\
\hline - Minimize harboring of bacteria & - Layered closure with absorbable monofilament \\
\hline \multirow[t]{2}{*}{ - Postoperative drains } & - Drains can be placed, but should be removed as early as possible \\
\hline & - Appropriate drain care to minimize contamination \\
\hline \multicolumn{2}{|l|}{ Postoperative care } \\
\hline \multirow[t]{2}{*}{ - Hospital stay } & - Stay overnight for intravenous antibiotics \\
\hline & - Discharge postoperative day I \\
\hline \multirow[t]{3}{*}{ - Follow-up } & - Avoid potential breast-skin contaminants \\
\hline & - Prophylactic antibiotics for bacteremic procedures \\
\hline & • Follow-up beyond 30 days \\
\hline
\end{tabular}

\section{References}

1. Cemal Y, Albornoz CR, Disa JJ, et al. A paradigm shift in U.S. breast reconstruction: part 2 - the influence of changing mastectomy patterns on reconstructive rate and method. Plast Reconstr Surg. 2013;131(3): 320e-326e.

2. Hanna KR, Tilt A, Holland M, et al. Reducing infectious complications in implant based breast reconstruction: impact of early expansion and prolonged drain use. Ann Plast Surg. 2016:76(Suppl 4):S312-S315.

3. Albornoz CR, Bach PB, Mehrara BJ, et al. A paradigm shift in U.S. breast reconstruction: increasing implant rates. Plast Reconstr Surg. 2013; 131(1):15-23.

4. Nguyen AT, Chang DW. Discussion: a paradigm shift in U.S. breast reconstruction: increasing implant rates. Plast Reconstr Surg. 2013; 131(1):24-25.

5. Colwell AS, Damjanovic B, Zahedi B, Medford-Davis L, Hertl C, Austen WG Jr. Retrospective review of 331 consecutive immediate single-stage implant reconstructions with acellular dermal matrix. Plast Reconstr Surg. 2011;128(6):1170-1178.

6. Alderman AK, Wilkins EG, Kim HM, Lowery JC. Complications in postmastectomy breast reconstruction: two-year results of the Michigan Breast Reconstruction Outcome Study. Plast Reconstr Surg. 2002;109(7):2265-2274.
7. Tadiparthi S, Staley H, Collis N, O'Donoghue JM. An analysis of the motivating and risk factors for conversion from implant-based to total autologous breast reconstruction. Plast Reconstr Surg. 2013;132(1): 23-33.

8. Kim JY, Davila AA, Persing S, et al. A meta-analysis of human acellular dermis and submuscular tissue expander breast reconstruction. Plast Reconstr Surg. 2012;129(1):28-41.

9. Spear SL, Howard MA, Boehmler JH, Ducic I, Low M, Abbruzzesse MR. The infected or exposed breast implant: management and treatment strategies. Plast Reconstr Surg. 2004;113(6):1634-1644.

10. Seng P, Bayle S, Vernier M, et al. Rib osteomyelitis: an uncommon complication of breast implant infection. J Plast Reconstr Aesthet Surg. 2015; 68(3):431-432.

11. Cohen JB, Carroll C, Tenenbaum MM, Myckatyn TM. Breast implantassociated infections: the role of the National Surgical Quality Improvement Program and the local microbiome. Plast Reconstr Surg. 2015;136(5):921-929.

12. Phillips BT, Bishawi M, Dagum AB, Khan SU, Bui DT. A systematic review of antibiotic use and infection in breast reconstruction. Plast Reconstr Surg. 2013;131(1):1-13.

13. Washer LL, Gutowski K. Breast implant infections. Infect Dis Clin North Am. 2012;26(1):111-125. 
14. Olsen MA, Chu-Ongsakul S, Brandt KE, Dietz JR, Mayfield J, Fraser VJ. Hospital-associated costs due to surgical site infection after breast surgery. Arch Surg. 2008;143(1):53-61.

15. Costa MA, Rommer E, Peric M, et al. Incidence of surgical-site infection is not affected by method of immediate breast reconstruction. Plast Reconstr Surg. 2013;132(1):20e-29e.

16. Netscher DT, Weizer G, Wigoda P, Walker LE, Thornby J, Bowen D. Clinical relevance of positive breast periprosthetic cultures without overt infection. Plast Reconstr Surg. 1995;96(5):1125-1129.

17. Pajkos A, Deva AK, Vickery K, Cope C, Chang L, Cossart YE. Detection of subclinical infection in significant breast implant capsules. Plast Reconstr Surg. 2003;111(5):1605-1611.

18. Armstrong RW, Berkowitz RL, Bolding F. Infection following breast reconstruction. Ann Plast Surg. 1989;23(4):284-288.

19. Reish RG, Damjanovic B, Austen WG Jr, et al. Infection following implant-based reconstruction in 1952 consecutive breast reconstructions. Plast Reconstr Surg. 2013;131(6):1223-1230.

20. Feldman EM, Kontoyiannis DP, Sharabi SE, Lee E, Kaufman Y, Heller L. Breast implant infections: is cefazolin enough? Plast Reconstr Surg. 2010;126(3):779-785.

21. Franchelli S, Vassallo F, Porzio C, et al. Breast implant infections after surgical reconstruction in patients with breast cancer: assessment of risk factors and pathogens over extended post-operative observation Surg Infect (Larchmt). 2012;13(3):154-158.

22. Johnson LB, Busuito MJ, Khatib R. Breast implant infection in a cat owner due to Pasteurella multocida. J Infect. 2000;41(1):110-111.

23. Manteca A, Pelaez AI, Garcia-Suarez MM, Hidalgo E, Lopez S, Mendez FJ. A rare case of silicone mammary implant infection by Streptomyces spp. in a patient with breast reconstruction after mastectomy: taxonomic characterization using molecular techniques. Diagn Microbiol Infect Dis. 2009;63(4):390-393.

24. De BK, Stauffer L, Koylass MS, et al. Novel Brucella strain (BO1) associated with a prosthetic breast implant infection. J Clin Microbiol. 2008; 46(1):43-49.

25. Macadam SA, Mehling BM, Fanning A, et al. Nontuberculous mycobacterial breast implant infections. Plast Reconstr Surg. 2007; 119(1):337-344

26. Reddy BT, Torres HA, Kontoyiannis DP. Breast implant infection caused by Trichosporon beigelii. Scand J Infect Dis. 2002;34(2): 143-144.

27. Wirth GA, Brenner KA, Sundine MJ. Delayed silicone breast implant infection with Mycobacterium avium-intracellulare. Aesthet Surg J. 2007; 27(2):167-171.

28. Scheflan M, Wixtrom RN. Over troubled water. Plast Reconstr Surg. 2016;137(1):97-105.

29. Vinh DC, Rendina A, Turner R, Embil JM. Breast implant infection with Mycobacterium fortuitum group: report of case and review. J Infect. 2006;52(3):e63-e67.

30. Spear SL, Seruya M. Management of the infected or exposed breast prosthesis: a single surgeon's 15 -year experience with 69 patients. Plast Reconstr Surg. 2010;125(4):1074-1084.

31. Constantine RS, Constantine FC, Rohrich RJ. The ever-changing role of biofilms in plastic surgery. Plast Reconstr Surg. 2014;133(6) $865 \mathrm{e}-872 \mathrm{e}$.

32. Burkhardt BR, Fried M, Schnur PL, Tofield JJ. Capsules, infection, and intraluminal antibiotics. Plast Reconstr Surg. 1981;68(1):43-49.

33. Hu H, Jacombs A, Vickery K, Merten SL, Pennington DG, Deva AK. Chronic biofilm infection in breast implants is associated with an increased T-cell lymphocytic infiltrate. Plast Reconstr Surg. 2015;135(2): 319-329.

34. Gfrerer L, Mattos D, Mastroianni M, et al. Assessment of patient factors, surgeons, and surgeon teams in immediate implant-based breast reconstruction outcomes. Plast Reconstr Surg. 2015;135(2): 245e-252e.

35. McCarthy CM, Mehrara BJ, Riedel E, et al. Predicting complications following expander/implant breast reconstruction: an outcomes analysis based on preoperative clinical risk. Plast Reconstr Surg. 2008;121(6):1886-1892.
36. Kato $\mathrm{H}$, Nakagami G, Iwahira $\mathrm{Y}$, et al. Risk factors and risk scoring tool for infection during tissue expansion in tissue expander and implant breast reconstruction. Breast J. 2013;19(6):618-626.

37. Wang F, Koltz PF, Sbitany H. Lessons learned from the American College of Surgeons National Surgical Quality Improvement Program database: has centralized data collection improved immediate breast reconstruction outcomes and safety? Plast Reconstr Surg. 2014;134(5): 859-868.

38. Weichman KE, Clavin NW, Miller HC, et al. Does the use of Biopatch devices at drain sites reduce perioperative infectious complications in patients undergoing immediate tissue expander breast reconstruction? Plast Reconstr Surg. 2015;135(1):9e-17e.

39. Butz DR, Lapin B, Yao K, et al. Advanced age is a predictor of 30-day complications after autologous but not implant-based postmastectomy breast reconstruction. Plast Reconstr Surg. 2015;135(2): 253e-261e.

40. Chun YS, Verma K, Rosen H, et al. Implant-based breast reconstruction using acellular dermal matrix and the risk of postoperative complications. Plast Reconstr Surg. 2010;125(2):429-436.

41. Francis SH, Ruberg RL, Stevenson KB, et al. Independent risk factors for infection in tissue expander breast reconstruction. Plast Reconstr Surg. 2009;124(6):1790-1796.

42. Selber JC, Wren JH, Garvey PB, et al. Critical evaluation of risk factors and early complications in 564 consecutive two-stage implant-based breast reconstructions using acellular dermal matrix at a single center. Plast Reconstr Surg. 2015;136(1):10-20.

43. Gnanadesigan N, Pechter EA, Mascola L. Listeria infection of silicone breast implant. Plast Reconstr Surg. 1994;94(3):531-533.

44. Nahabedian MY, Tsangaris T, Momen B, Manson PN. Infectious complications following breast reconstruction with expanders and implants. Plast Reconstr Surg. 2003;112(2):467-476.

45. Scalise A, Calamita R, Tartaglione C, et al. Improving wound healing and preventing surgical site complications of closed surgical incisions: a possible role of incisional negative pressure wound therapy - systematic review of the literature. Int Wound J. Epub 2015 Oct 1.

46. Kearney AM, Brown MS, Soltanian HT. Timing of radiation and outcomes in implant-based breast reconstruction. J Plast Reconstr Aesthet Surg. 2015;68(12):1719-1726.

47. Sbitany H, Wang F, Peled AW, et al. Immediate implant-based breast reconstruction following total skin-sparing mastectomy. Plast Reconstr Surg. 2014;134(3):396-404.

48. Peled AW, Itakura K, Foster RD, et al. Impact of chemotherapy on postoperative complications after mastectomy and immediate breast reconstruction. Arch Surg. 2010;145(9):880-885.

49. Alderman A, Gutowski K, Ahuja A, Gray D. ASPS clinical practice guideline summary on breast reconstruction with expanders and implants. Plast Reconstr Surg. 2014;134(4):648e-655e.

50. Khansa I, Hendrick RG Jr, Shore A, Meyerson J, Yang M, Boehmler JH 4 th. Breast reconstruction with tissue expanders : implementation of a standardized best-practices protocol to reduce infection rates. Plast Reconstr Surg. 2014;134(1):11-18.

51. Nahabedian MY. Discussion: over troubled water - an outbreak of infection due to a new species of Mycobacterium following implant-based breast surgery. Plast Reconstr Surg. 2016;137(1):106-107.

52. Showalter BM, Crantford JC, Russell GB, et al. The effect of reusable versus disposable draping material on infection rates in implant-based breast reconstruction: a prospective randomized trial. Ann Plast Surg. 2014;72(6):S165-S169.

53. Olmsted RN. Pilot study of directional airflow and containment of airborne particles in the size of Mycobacterium tuberculosis in an operating room. Am J Infect Control. 2008;36(4):260-267.

54. Andersson AE, Bergh I, Karlsson J, Eriksson BI, Nilsson K. Traffic flow in the operating room: an explorative and descriptive study on air quality during orthopedic trauma implant surgery. Am J Infect Control. 2012;40(8):750-755.

55. Mangram AJ, Horan TC, Pearson ML, Silver LC, Jarvis WR. Guideline for prevention of surgical site infection, 1999. Am J Infect Control. 1999; 27(2):97-134 
56. Clayton JL, Bazakas A, Lee CN, Hultman CS, Halvorson EG. Once is not enough: withholding postoperative prophylactic antibiotics in prosthetic breast reconstruction is associated with an increased risk of infection. Plast Reconstr Surg. 2012;130(3):495-502.

57. Avashia YJ, Mohan R, Berhane C, Oeltjen JC. Postoperative antibiotic prophylaxis for implant-based breast reconstruction with acellular dermal matrix. Plast Reconstr Surg. 2013; 131(3):453-461.

58. Rubino C, Brongo S, Pagliara D, et al. Infections in breast implants: a review with a focus on developing countries. J Infect Dev Ctries. 2014; 8(9):1089-1095.

59. Silvestri L, van Saene HK, Parodi PC. Decolonization strategies to control Staphylococcus aureus infections in breast implant surgery. Plast Reconstr Surg. 2011;128(1):328-329.

60. Mirzabeigi MN, Lee M, Smartt JM Jr, Jandali S, Sonnad SS, Serletti JM. Extended trimethoprim/sulfamethoxazole prophylaxis for implant reconstruction in the previously irradiated chest wall. Plast Reconstr Surg. 2012;129(1):37e-45e.

61. Kalus R, Swartz JD, Metzger SC. Optimizing safety, predictability, and aesthetics in direct to implant immediate breast reconstruction: evolution of surgical technique. Ann Plast Surg. 2016;76(Suppl 4):S320-S327.

62. Basta MN, Gerety PA, Serletti JM, Kovach SJ, Fischer JP. A systematic review and head-to-head meta-analysis of outcomes following directto-implant versus conventional two-stage implant reconstruction. Plast Reconstr Surg. 2015;136(6):1135-1144.

63. Brand KG. Infection of mammary prostheses: a survey and the question of prevention. Ann Plast Surg. 1993;30(4):289-295.

64. Jacombs A, Tahir $\mathrm{S}, \mathrm{Hu} \mathrm{H}$, et al. In vitro and in vivo investigation of the influence of implant surface on the formation of bacterial biofilm in mammary implants. Plast Reconstr Surg. 2014;133(4):471e-480e.

65. Chang DW, Barnea Y, Robb GL. Effects of an autologous flap combined with an implant for breast reconstruction: an evaluation of 1000 consecutive reconstructions of previously irradiated breasts. Plast Reconstr Surg. 2008;122(2):356-362.

66. Webster J, Osborne S. Preoperative bathing or showering with skin antiseptics to prevent surgical site infection. Cochrane Database Syst Rev. 2006;(2):CD004985.

67. Craft RO, Damjanovic B, Colwell AS. Evidence-based protocol for infection control in immediate implant-based breast reconstruction. Ann Plast Surg. 2012;69(4):446-450.

68. Perona PJ, Johnson AJ, Perona JP, et al. Effectiveness of various hospitalbased solutions against community-acquired methicillin-resistant Staphylococcus aureus. J Long Term Eff Med Implants. 2013;23(1):23-29.

69. Darouiche RO, Wall MJ Jr, Itani KM, et al. Chlorhexidine-alcohol versus povidone-iodine for surgical-site antisepsis. N Engl J Med. 2010; 362(1):18-26.

70. Courtiss EH, Goldwyn RM, Anastasi GW. The fate of breast implants with infections around them. Plast Reconstr Surg. 1979;63(6): 812-816.

71. Collis N, Mirza S, Stanley PR, Campbell L, Sharpe DT. Reduction of potential contamination of breast implants by the use of 'nipple shields'. Br J Plast Surg. 1999;52(6):445-447.

72. Pfeiffer P, Jørgensen S, Kristiansen TB, Jørgensen A, Hölmich LR. Protective effect of topical antibiotics in breast augmentation. Plast Reconstr Surg. 2009;124(2):629-634.
73. Adams WP Jr, Rios JL, Smith SJ. Enhancing patient outcomes in aesthetic and reconstructive breast surgery using triple antibiotic breast irrigation: six-year prospective clinical study. Plast Reconstr Surg. 2006; 118(7 Suppl):46S-52S.

74. Netscher DT. Subclinical infection as a possible cause of significant breast capsules. Plast Reconstr Surg. 2004;113(7):2229-2230.

75. Yalanis GC, Liu EW, Cheng HT. Efficacy and safety of povidone-iodine irrigation in reducing the risk of capsular contracture in aesthetic breast augmentation. Plast Reconstr Surg. 2015;136(4):687-698.

76. Wiener TC. The role of Betadine irrigation in breast augmentation. Plast Reconstr Surg. 2007;119(1):12-15.

77. Losken A. Early results using sterilized acellular human dermis (Neoform) in post-mastectomy tissue expander breast reconstruction. Plast Reconstr Surg. 2009;123(6):1654-1658.

78. Nahabedian MY.AlloDerm performance in the setting of prosthetic breast surgery, infection, and irradiation. Plast Reconstr Surg. 2009;124(6):1743-1753.

79. Vardanian AJ, Clayton JL, Roostaeian J, et al. Comparison of implantbased immediate breast reconstruction with and without acellular dermal matrix. Plast Reconstr Surg. 2011;128(5):403e-410e.

80. Sbitany H, Serletti JM. Acellular dermis-assisted prosthetic breast reconstruction: a systematic and critical review of efficacy and associated morbidity. Plast Reconstr Surg. 2011;128(6):1162-1169.

81. Ranganathan K, Santosa KB, Lyons DA, et al. Use of acellular dermal matrix in postmastectomy breast reconstruction: are all acellular dermal matrices created equal? Plast Reconstr Surg. 2015;136(4):647-653.

82. Gentileschi S, Bracaglia R, Garganese G, et al. Immediate definitive prosthetic reconstruction in patients with ptotic breasts. Ann Plast Surg. 2013;70(2):144-148.

83. Lewis P, Jewell J, Mattison G, Gupta S, Kim H. Reducing postoperative infections and red breast syndrome in patients with acellular dermal matrix-based breast reconstruction: the relative roles of product sterility and lower body mass index. Ann Plast Surg. 2015;74 Suppl 1:S30-S32.

84. Newman MI, Hanabergh E, Samson MC. AlloDerm performance in the setting of prosthetic breast surgery, infection, and irradiation. Plast Reconstr Surg. 2010;126(3):1120-1121.

85. Shestak KC, Askari M. A simple barrier drape for breast implant placement. Plast Reconstr Surg. 2006;117(6):1722-1723.

86. Moyer HR, Ghazi B, Saunders N, Losken A. Contamination in smooth gel breast implant placement: testing a funnel versus digital insertion technique in a cadaver model. Aesthet Surg J. 2012;32(2):194-199.

87. McCarthy CM, Disa JJ, Pusic AL, Mehrara BJ, Cordeiro PG. The effect of closed-suction drains on the incidence of local wound complications following tissue expander/implant reconstruction: a cohort study. Plast Reconstr Surg. 2007;119(7):2018-2022.

88. Murray JD, Elwood ET, Jones GE, Barrick R, Feng J. Decreasing expander breast infection: a new drain care protocol. Can J Plast Surg. 2009;17(1):17-21.

89. Leyngold MM, Stutman RL, Khiabani KT, et al. Contributing variables to post mastectomy tissue expander infection. Breast J. 2012;18(4):351-356.

90. Javaid M, Shibu M. Breast implant infection following nipple piercing. Br J Plast Surg. 1999;52(8):676-677.

91. Hunter JG, Padilla M, Cooper-Vastola S. Late Clostridium perfringens breast implant infection after dental treatment. Ann Plast Surg. 1996; 36(3):309-312.
Breast Cancer - Targets and Therapy

\section{Publish your work in this journal}

Breast Cancer - Targets and Therapy is an international, peerreviewed open access journal focusing on breast cancer research, identification of therapeutic targets and the optimal use of preventative and integrated treatment interventions to achieve improved outcomes, enhanced survival and quality of life for the cancer patient.

\section{Dovepress}

The manuscript management system is completely online and includes a very quick and fair peer-review system, which is all easy to use. Visit http://www.dovepress.com/testimonials.php to read real quotes from published authors. 